\title{
Pengaruh Pendekatan Realistic Mathematic Education Secara E-Learning Terhadap Hasil Belajar Matematika
}

\author{
Findy Soraya ${ }^{1}$, Restu Ria Wantika ${ }^{2}$ \\ 1Program Studi Pendidikan Matematika, Universitas PGRI Adi Buana, Surabaya, Indonesia; \\ *sfindysoraya50@gmail.com, \\ 2Program Studi Pendidikan Matematika, Universitas PGRI Adi Buana, Surabaya, Indonesia; \\ restu@unipasby.ac.id
}

\begin{abstract}
Abstrak. Latar belakang diakukannya penelitian ini yakni kurangnya penguasaan peserta didik dalam memecahkan masalah berupa cerita yang berhubungan dengan permasalahan kehidupan, dan sulitnya mengaplikasikan pembelajaran ke dalam kehidupan keseharian, terlebih pada mata pelajaran matematika. Diterapkannyaa pendekatan realistic mathematic education secara e-learning adalah salah satu cara untuk menanganii masalah yyang sudah diuraikan, khususnya dimasa pandemi Covid-19. Tujuan dilakukannya penelitian adalah untuk melihat terdapat pengaruh atau tidak terdapat pengaruh penerapan pendekatan realistic mathematic education terhadap hasil belajar matematika. Dalam penelitian ini digunakan jenis penelitian kuantitatif dengan metode penelitian eksperimental yang dilaksanakan di SMA Negeri 1 Menganti. Dalam penelitian kali ini digunakan teknik ppurposive sampling, Sampel kelas eksperimen yaitu kelas X IPA 1 dan untuk kelas kontrol yaitu kelas XXIPA 2. Berdasarkan hasil analisis ditunjukkan rrata-rata hasil belajar matematika kelas eeksperimen lebih ttinggi daripada kelas kontrol yaitu diperoleh $\mathrm{t}$ hitung $>\mathrm{t}$ tabel yaitu 5,50 $>1,99$ sehingga $H_{0}$ ditolak terdapat pengaruh pendekatan realistic mathematic education secara e-learning terhadap hasillbelajarrmatematika.
\end{abstract}

Kata Kunci: realistic mathematic education, e-learning, hasil belajar matematika

\begin{abstract}
The background of this research is the lack of mastery of students in solving problems in the form of stories related to life problems, and the difficulty of applying learning to everyday life, especially in mathematics. The application of the realistic mathematic education approach by e-learning is one way to deal with the problems that have been described, especially during the Covid-19 pandemic The purpose of this research is to see whether or not there is an effect of applying the realistic mathematic education approach to mathematics learning outcomes. This research uses quantitative research with experimental research methods carried out in SMA Negeri 1 Menganti. In this study, a purposive sampling technique was used. The sample in this study was for the experimental class, namely class X IPA 1 and for the
\end{abstract}

This is an open access article under the $C C-B Y-S A$ license 
control class, namely class X IPA 2. Based on the results of the t-test analysis, it is shown that the average result of learning mathematics in the experimental class is higher than the control class and the results of data analysis are obtained $t$ count $>t$ table, namely 5.50> 1.99 so that $\mathrm{H}_{0}$ is rejected, there is an effect of the realistic mathematical education approach. -learning of mathematics learning outcomes

Keywords: realistic mathematics education, e-learning, mathematics learning outcomes

\section{Pendahuluan}

Pendidikan sangatlah penting dan harus dilaksanakan dengan sebaikbaiknya. Karena pendidikan adalah suatu keperluhan absolut yang wajib terpenuhi sepanjang hayat dan berlangsung dalam lingkungan sekitar. Dalam pendidikan seorang guru adalah kunci yang dapat membuat seorang pelajar mampu mencapai dan menjalankan tujuan hidupnya. Dengan ini seorang guru wajib mewujudkan proses belajar mengajar yang inovatif, aktif, kreatif, bermakna, menarik serta mudah diterapkan oleh seorang pelajar dalam kesehariannya. Dalam suatu kehidupan, manusia selalu dihadapi banyak permasalahan namun tidak semua tentang permasalahan matematis yang dihadapi oleh manusia. Meskipun begitu matematika mempunyai kedudukan yang amat fundamental guna memecahkan masalah manusia dalam kesehariannya (Kusumawati \& Morina Turisia, 2014).

Akan tetapi, sesungguhnya banyak didapatkan seorang pelajar belum bisa menerapkan hasil yang didapat selama proses pembelajaran kedalam kegiatan kesehariannya terlebih pada pelajaran matematika. Terjadinya masalah tersebut bermula dari terlaksananya proses belajar mengajar matapelajaran matematika dalam kelas tengah dikontrol oleh seorang pendidik, dengan menerapkan metode pengajaran dan pendekatan pembelajaran konvensional. Dengan adanya pembelajaran konvensional seorang pelajar condong pasif selama menerima materi yang dijelaskan mereka hanya menerima bahan jadi dari guru sehingga seorang pelajar kesulitan untuk memahami pelajarannya.

Dalam berlangsungnya pelajaran matematika seringkali dijumpai siswa sedang mengalami kesusahan atau ketidak mampuan untuk mengidentifikasi dan menyelesaikan permasalahan soal cerita yang berhubungan dengan permasalahan kehidupan. Khususnya pada matematika kelas X SMA/SMK yang terdapat beberapa materi yang penyampaian materinya berhubunngan

Copyright (C) 2021

Buana Matematika :

Jurnal Ilmiah Matematika dan Pendidikan Matematika 
dengan permasalahan kehidupan sehari-hari serta penyajiannya dalam bentuk cerita, salah satunya adalah materi sistemmpersamaan dan pertidaksamaannlinear. Savitri et al. (2018) Mengemukakan bahwa siswa kelas MIPA di SMAN 2 Purworejo mengalami kesalahan pemberian tanda dalam menyelesaikan soal pertidaksamaan. Penelitian yang dilakukan oleh Muchsin et al. (2020) mengemukakan bahwa peserta didik kelas X MIA 6 SMA Negeri 4 Kota Ternate lemah untuk memahami konsep dasar terutama dalam menuliskan informasi dari suatu permasalahan yang berkaitan dengan pertidaksamaan. Dari gambaran masalah yang sudah dijabarkan menandakan matematika sangat diperlukan seorang pelajar agar bisa diaplikasikan dalam kehidupan keseharian untuk memecahkan suatu permasalahan.

Dengan ini sehingga diperlukan suatu cara guna melancarkan seorang pelajar dalam memahami pelajaran dengan pengalamannya sendiri, yaitu dengan mengaplikasikan pendekatan yang menjadikan seorang pelajar mampu menyambungkan pembelajaran matematika dengan kehidupan kesehariannya. Menurut Musfiqon \& Nursyansyah (2015) menyatakan, "pendekatan pembelajaran adalah suatu kumpulan metode serta cara yang dipakai seorang pendidik dalam melakukan proses pembelajaran. Berdasarkan uraian tersebut diperlukan pemilihan pendekatan yang memiliki karakteristik yang sesuai dengan masalah, melihat masalah yang telah diurakan sebelumnya diperlukan sebuah pendekatan pembelajaran yang dalam proses belajar mngajar menerapkan atau menggunakan konteks dunia nyata sebagai topik pembelajarannya, serta dalam pembelajarannya menggunakan permasalahan yang realistic atau suatu permasalahn kontekstual.

Berdasarkan uraian kriteria pendekatan yang dibutuhkan untuk mengatasi suatu permasalahan yang ada, penerapan pendekatan realistic mathemathic education dalam suatu kegiatan pembelajaran di kelas adalah sebuah solusi yang cocok untuk menangani permasalahan tersebut. Hal ini dikarenakan suatu kriteria yang dibutuhkan untuk mengatasi suatu permasalahan yang sedang terjadi sesuai dengan karakteristik pendekatan realistic mathemathic education. Menurut Fitriani \& Permana (2019) karakteristikapendekatan realistic mathemathic education yaitu pembelajaran belangsung menggunakan permasalahan kontekstual,sselama proses pembelajarn menggunakan model pembelajaran, selama pembelajaran melibatkan kontribusi siswa, adanya interaksi diantara seorang guru dan seorang pelajar selama kegiatan belajar megajar berlangsung, serta pembelajarannya 
terintegrasi dengan topik yang lainnya. Selain dari karakteristiknya realistic mathemathic education juga memiliki pengertian yang sesuai dengan permasalahan diatas yaitu pembelajaran yang menggunakan situasi kehidupan nyata sebagai pokok pembelajaran. Artinya proses pembelajaran yang berlangsung dengan menggunakan pendekatan realistic mathemathic education serta materi atau topik pembelajaran harus disesuaikan dengan pengalaman peserta didik dalam kesehariannya.

Pendekatan ini meruakan pendekatan pembelajaran yang dalam penerapan materinya selalu berkaitan dengan keseharian peserta didik dan bersifat realistic atau nyata. Realistic mathemathic education mempunyai tiga prinsip antara lain guided reinventionn trough progressive phenomenology ,ddidactical phenomenology,sself developed models.Ketigaaprinsip tersebut dioperasionalkan kedalam karakteristik realistic mathemathic education, sebagai berikut: (1) the use contex, Pembelajaran diawali dengan memberikan masalah nyata sebagai fokus awal dari kegiatan belajar. (2) use models, bridging by vertiinstruments, model digunakan sebagai peghubung antara nyata dan khayalan yang dapat menolong peserta didik dalam memahami matematika dengan menggunakan cara yang berbeda-beda. (3) student contribution, dalam proses pembelajarnnya kontribusi yang besar sangat diharapkan datangnya dari siswa bukan dari seorang pendidik. (4) interactivity, dalam pembelajarannya komunikasi seorang pendidik dengan peserta didik adalah suatu hal pokok pada realistic mathematics education. Secara akurat wujud dari hubungan ini dapat berupa suatu penguraian, sepakat, tidak sepakat, negosiasi, persoalan, pembenaran, atau perenungan guna mendapatkan sebuah ketuntasan belajar peserta didik (5) interwining, pada realistic mathematics education penggabungan unsur-unsur matematika sangatlah penting (Ningsih, 2014).

Adapun langkah-langkah pendekatan realistic mathemathic education antara lain (1) memahami permasalahan yang bersifat nyata, Guru menyampaikan suatu masalah nyata dan peserta didik mencerna suatu masalah. (2) memberi penjelasan dari sutau permasalahan nyata, guru memberi penjelasan konteks soal dengan menunjukkan sebuah petunjuk sedikit saja hingga peserta didik mengerti maksud masalah. (3) menyelesaikan permasalahan nyata, seorang guru memotivasi serta memberikan semangat kepada siswa untuk menyelesaikan suatu permasalahan nyata dengan mandiri. (4) seorang guru menyediakan peluang kepada seorang pelajar untuk membandingkan dan Copyright $\odot 2021$

Buana Matematika :

Jurnal Ilmiah Matematika dan Pendidikan Matematika 
mendiskusikan jawaban bersama-sama. (5) seorang guru mengajak peserta didik menarik sebuah kesimpulan dari hasil diskusi yang sudah berlangsung, memberikan arahan agar seorangg pelajar dapat menarik sebuah kesimpulan dari inti dari proses pembelajaran yang sudah berlangsung, disini seorang guru hanyalah bertindak sebagai pembimbing. Berdasarkan hhasil penelitiann yang dilakukan oleh Sukri \& Widjajanti (2015) mengatakan bahwa penerapan pendekatan realistic mathemathic education pada pelajaran matematika dapat memberikan pengaruh ypositif terhadap motivasi dan prestasi belajar dan peserta didik berperan aktif dalamn kesuksesan proses belajar mengajar.

Hal ini menandakank dengan adanya penerapan pembelajaran yang menggunakan konteks dunia nyataa dapat meningkatkan hasill belajar peserta didik. Hasill belajarradalah suatu karakter yang didapat seorang pelajar setelah belajar, yang dijadikan sebagai suatu patokan untuk melihat tingkat keberhasilan peserta didik setelah melakukan pembelajaran (Hasan et al., 2020). Hasil belajar dipengaruhi oleh beberapat faktorr antara lain ada dari dalam dan dari luar kehidupan di lingkungan sekitar, dengan adanya pesertaadidik yang mmemiliki kemampuan untuk menyelesaikan masalah kesehariannya maka seorang peserta didik dapat meningkatkan hasil belajarnya terlebih pada materi matematika, Sehingga hasil belajar merupakan suatu bagian paling penting yang wajib diperdulikan seorang pendidik dan perlu terus ditingkatkan dalam semua pembelajaran khususnya pembelajaran matematika. Menurut Suharsimi (dalam Wijaya \& Arsyah, 2015) Hasil belajar adalah sesuatu yang didapatssetelah proses belaar mengajar berjalan, hasilbbelajar ini berupa angka, kata-kata seperti: sengat baik, baik, cukup, kurang baik, dan sangat kurang baik atau bisa berupa huruf. Dengan adanya keterangan hasil belajar tersebut bisa diketahui apakah seorang peserta didik tersebut sudah dapat mencapai tujuannya dalam proses pembelajaran atau masih perlu ditingkatkan lagi minat dalam belajarnya. Dari hasil belajar yang diperoleh seorang pendidik bisa mengetahui apakah model dan pendekatan yang digunakan selama proses belajar mengajar mencapai kesuksesan, serta dapat menjadikan bahan evaluasi seorang pendidik. Karena adanya pesertaddidik yangg memiliki hasilbbelajar yang bagus atau pelajar yang memiliki prestasi sangat bagus diinginkan mampu menciptakan seorang pelajar yang mempunyai keahlian yang inovatif dan keatif agar dapat bersaing di era globalisasi serta mengikuti perkembangan IPTEK dan dapat menerapkan IPTEK dalam duniaapendidikan (Budiman, 2017). Terlebih pada pandemi covid-19 dimana masa yang menuntut proses pembelajaran serta

Copyright (C) 2021

Buana Matematika :

Jurnal Ilmiah Matematika dan Pendidikan Matematika 
komunikasi guru dengan peserta didik dilaksanakan secara e-learning. Masa pendemi covid-19 merupakan salah satu sebab penelitian ini dilaksanakan secara e-learning.

E-learning dianggap suatu kegiatan belajar mengajar seorang guru dengan peserta didik yang menggunakan sebuah teknologi informasi dengan sarana telekomunikasi dan multimediaasebagai media utama dalam penyampaian materi dan interaksi pembelajaran,ssalah satunyaaadalah mediassosial (Zakia et al., 2019). E-learning merupakan sebuah prosedur berlangsungnya suatu aktivitas pembelajaran diantara guru dan peserta didik yang dilaksanakan secara jarak jauh serta menggabungkan dasar-dasar sistem pembelajaran menggunakan teknologi. Menurut Ibrahim \& Suardiman (2014) dalam dunia pendidikannseorang pendidik menerapkan teknologi dalammpembelajaran atau bisa disebut e-learninggartinya pembelajaran yang pelaksanaannya menggunakan alat-alat elektronik yang dipadukan dengan konten pembelajaran sehingga menghasilan sebuah produkkyang bisa dimanfaatkan untuk kegiatan pembelajaran. Agar pembelajaran bisa menarik, inovatif, kreatif, aktif, serta bermakna dan tetap bisa dilaksanakan selama masa pandemi covid-19 maka akan diterapkan pendekatan realistic mathemathic education dengan berbasis e-learning. Pendekatan realistic mathemathic education secara e-learning ini tetap dilaksanakan sesuai dengan prinsip, karakteristik, dan langkah-langkahnya, hanya saja pelaksanaannya yang dilaksanakan secara e-learning. Dengan adanya pembelajaran menggunakan pendekatan realistic mathemathic education secara e-learning proses pembelajaran tetap berlangsung. Berdasarkan penelitian yang dilakukan oleh Nolaputra et al (2018) mengemukakan bahwa peserta didik yang dikenai model pembelajaran PBL dengan menggunakan pendekatan RME berbantuan schoology telah mencapai ketuntasannklasikal, peserta didik yang diberi perlakuan sesuai pendekatan realistic mathemathic education memiliki kemampuan literasi yang lebih tinggi. Hal ini menandakan bahwa pendekatan realistic mathemathic education secara e-learning bisa dilaksanakan. Hal inilah yang mendasari pemikiran penulis dilakukannya penelitian dengan tujuan untuk mengetahui pengaruh pendekatan realistic mathemathic education secara e-learning terhadap hasil belajar matematika pada materi sistem pertidaksamaan linear dua variabel.

\section{Metode}

Copyright (C) 2021

Buana Matematika :

Jurnal Ilmiah Matematika dan Pendidikan Matematika 
Metode yang digunakan dalam penelitiannini adalah penelitiann kuantitatif menggunakan metode eksperimen. Menurut Sugiyono (2015:107), "metodeppenelitian eksperimenn bisa didefinisikan sebuah metode yangl dipakai guna mencari pengaruhh perlakuan tertentu terhadap yang lain dalam kondisi yang terkendalikan." Penelitiannya menggunakan Post Tes Only Design yang diterapkan ppada siswaa KelasXX. Pada desain posttes terdapat duaakelas yaituu kelas pertama yang diberikan perlakuann $(X)$ dinamakan kelase eksperimen dan kelas kedua tidak diberikan perlakuan dinamakan kelask kontrol (Sugiyono, 2015: 114). Untuk mengetahuippengaruh perlakuanyyang telah diberikan digunakan analisis statistik t-test. Jika hasil analisis menunjukkan tterdapat perbedaann diantara kelase eksperimen dan kelass kontrol, maka perlakuan yang diberikanlberpengaruh secara signifikan. Desain penelitian ini dapat digambarkan sebagai berikut.

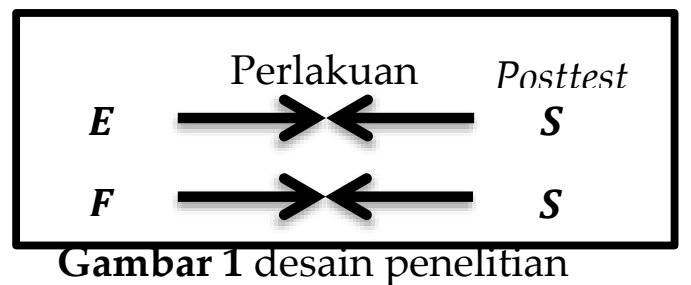

Penjelasan:

Gambar 1 desain penelitian

$\mathrm{E}=$ Kelas Eksperimen (kelass yang diberikan perlakuan pendekatan irealistic mathemathic ieducation)

$\mathrm{F}=$ Kelas Kontrol (kelass yang diberikan iperlakuan pendekatan saintifik)

$\mathrm{S}=$ Tes Akhir (posttest)

Adapun langkah-langkah yang dilaksanakan selama berlangsungnya penelitian eksperimen yaitu memilih dua kelompok kelas kemudian menentukan kelas pertama dan kelas kedua. Selanjutnya memberikan perlakuan pendekatan realistic mathemathic education di kelompok pertama, pendekatan saintifik pada kelompok dua. Kemudian dilanjut dengan memberikan posttest kepada kedua kelas secara bersama-sama guna melihat hasil belajar, kemudian dilakukan analisis data skor tes dan mengambil kesimpulan.

Populasinya adalah siswa kelas X SMA Negeri 1 Menganti Tahun pelajaran 2020/2021. Teknik pengambilan sampel digunakan teknik Nonprobability Sampling. Jenis Nonprobability Sampling adalah teknik pengambilan purposive sampling. Penelitian kali ini digunakan sampel kelas XXIPAA1 sebagai kelaseeksperimen yang akan diberikann perlakuan berupap 
pendekatan realistic mathemathic education dan XXIPAA2 sebagai kelasskontrol yang akan diberikan perlakuan berupa pendekatan saintifik. Variabel yang digunakan yaitu variabell independenn(varibel bebas) dan varibell dependenn (terikat). Variabel independennya adalah pendekatan realistic mathemathic education, dependennya adalah hasil belajar matematika. Bentuk tes yang digunakan yaitu soal tes berbentuk uraian (essay) sebagai bahan penilaian untuk peningkatan hasil belajar. Pada dasarnya penelitian ini dilakukan untuk mengetahuii terdapat atau tidakk terdapat perbedaan nhasil belajari antara pesertaadidik yang diajar dengann menerapkann pendekatann realistic mathemathic education dengan pesertaadidik yang diajarr dengan menerapkan pendekatann Saintifik, secara e-learning.

Setelah diperoleh data, data tersebut dianalisis menggunakan metode analisis statistika, teknis analisis data menggunkan rumus uji-t karena dalam penelitian ini menggunakan penelitian kuantitatif. Menurut Astutik \& Fitriatien (2016) dalam analisis ini terdapat syarat yaitu data setiap variabel yang dianalisis haruss berdistribusi normal. Maka dari itu terlebihh dahulu dilakukann pengujiann normalitasa data ddengan menggunakani rumus chi kuadrat, setelah dihasilkan sebuah data yang berdistribusio normall maka idilanjutkan dengann menguji homogenitaskkedua varianss menggunakan uji F. Selanjutnya adalah uji hipotesis guna mengetahui pengaruh pendekatan rrealistic mathemathic eeducation secara e-learning terhadap hasilbbelajar matematika dengan menggunakan rumus uji-t. Hipotesis dari dilaksanakannya penelitian kali ini merupakan terdapat pengaruh pendekatan realistic mathemathic education secara e-learning terhadap hasil belajar matematika.

\section{Hasil dan Pembahasan}

Penelitian dilaksanakan di SMA Negeri 1 Menganti yang memakai populasi kelas X IPA sejumlah 252 siswa. Berdasarkan pertimbangan peneliti dari populasi tersebut diambil 2 kelas yakni kelaseeksperimen menggunakan $X$ IPA 1 sebanyak 360siswa sedangkan kelasskontrol menggunakan X IPA 2 sebanyak 360siswa. Peneliti memberikan perlakuan pada kelas eksperimen berupa pendekatan realistic mathemathic education secara e-learning. Peneliti juga memberikan perlakuan pada kelas control berupa pendekatan saintifik secara e-learning. Adapun yang diteliti mengenai pengaruh pendekatan realistic mathemathic education secara e-learning terhadap hasilb belajar Copyright $\odot 2021$

Buana Matematika :

Jurnal Ilmiah Matematika dan Pendidikan Matematika 
matematikaapada materiisistem ppertidaksamaan linearrdua variabel. Instrument penelitian yang digunakann adalah tess hasil belajar yang terdiri dari empat butir soal berbentuk uraian. Instrument tersebut telah divalidasi oleh Drs. Hery Suharto selaku guru pamong matematika kelas X SMA Negeri 1 Menganti dan Nur Fathonah, S.Pd., M.Pd. selaku dosen Pendidikan MMatematika Universitas PGRI Adi BBuana Surabaya. Penelitianiini dimulai bulan November 2020 dan berakhir pada bulan Desember 2020. Data iyang ddipakai dalam peneltianiini adalah data hasil evaluasi (posttest).

Dalam uji normalitas didapatkan jumlah nilai kelas eksperiman sebesar 2.760 dengan rata-ratainilai siswa sebesarr 76,67 sedangkan pada kelaskkontrol didapatkan jumlah nilas sebesar 2.300 dengan rata-rata nilai siswa sebesar 63,89. Dalam uji normalitas Hasil Belajar didapatkan hasil sepertii tabel berikut.

Tabel 1 Hasil Uji Normalitas Hasil Belajar

\begin{tabular}{cccc}
\hline Variabel & $\chi_{\text {hitung }}^{2}$ & $\chi_{\text {tabel }}^{2}$ & Kesimpulan \\
\hline Kelas Eksperimen & 9,74 & 11,07 & Normal \\
Kelas Kontrol & 6,30 & 11,07 & Normal \\
\hline
\end{tabular}

Uji Normalitas untuk kelas eksperimen diperoleh $\chi_{\text {hitung }}^{2}<\chi_{\text {tabel }}^{2}=9,74<$ 11,07. Sedangkan untuk kelas kontrol diperoleh $\chi_{\text {hitung }}^{2}<\chi_{\text {tabel }}^{2}=6,30<11,07$. Dari hasil uji normalitas dapat ditarik sebuah kesimpulan bahwa kedua kelas tersebut berdistribusi normal.

Dalam uji homogenitas didapatkan perhitungan seperti pada tabel berikut: Tabel 2 Nilai Homogenitas

\begin{tabular}{cccc}
\hline Kelompok & Banyak Data & Rata - Rata & Simpangan Baku \\
\hline Eksperimen & 36 & 76,67 & 9,28 \\
Kontrol & 36 & 63,89 & 11,40 \\
\hline
\end{tabular}

Uji Homogenitas dalam penelitian ini diperoleh varian hasil tes Hasil Belajar matematika yang diajarkan menggunakan pendekatan realistic mathematics education secara e-learning dan hasil tes Hasil Belajar metematika yang diajarkan menggunakan pendekatan saintifik secara e-learning pada taraf $\alpha=$ 0,05 dan $\mathrm{dk}_{1}=\mathrm{dk}_{\text {pembilang }}=35 \mathrm{dan}_{\mathrm{dk}}=\mathrm{dk}_{\text {penyebut }}=35$ maka diperoleh $F_{\text {hitung }}=$ 1,51 dan $F_{\text {tabel }}=1,76$. Hal ini menunjukkan bahwa $F_{\text {hitung }}<\mathrm{F}_{\text {tabel }}$ atau 1,51< 1,76 maka bisa ditarik kesimpulan bahwa kedua varians tersebut homogen.

Dalam uji hipotesis dan uji-t peneiti menggunkan kriteria pengujian sebagai berikut:

Copyright (C) 2021

Buana Matematika :

Jurnal Ilmiah Matematika dan Pendidikan Matematika 


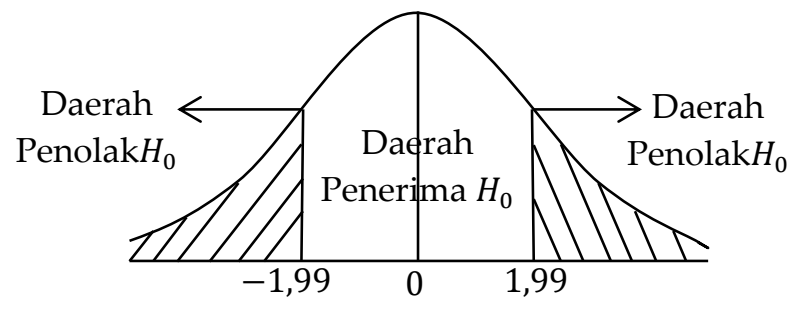

Gambar 2 Uji Dua Arah

$H_{0}$ diterima jika $-t_{\frac{\alpha}{2}} ; n_{A}+n_{B}-2 \leq t_{\text {hitung }} \leq t_{\frac{\alpha}{2} ; n_{A}+n_{B}-2}$

$H_{0}$ diolak jika $t_{\text {hitung }}<-t_{\frac{\alpha}{2} ; n_{A}+n_{B}-2}$ atau $t_{\text {hitung }}>t_{\frac{\alpha}{2} ; n_{A}+n_{B}-2}$

Dan rumusan hipotesis sebagai berikut:

$H_{0}: \mu_{1}=\mu_{2} \quad$ (Tidak terdapat perbedaan hasil

belajar matematika diantara peserta didik yang diajarkan dengan pendekatan realistic mathemathic education secara e-learning dengan pendekatan saintifik secara e-learning)

$H_{0}: \mu_{1} \neq \mu_{2} \quad$ (Terdapat perbedaan hasil belajar

matematika diantara peserta didik yang diajarkan dengan pendekatan realistic mathemathic education secara e-learning dengan pendekatan Saintifik secara e-learning)

Dengan imenggunakan taraff signifikann $\alpha=0,05$ dengan derajattkebebasan $\mathrm{dk}=\mathrm{n} \_\mathrm{A}+\mathrm{n} \_\mathrm{B}-2$ maka diperoleh $\mathrm{t}$ _hitung=5,50 dan $\mathrm{t}$ _tabel=1,99. Hal itu berarti menunjukkan bahwa t_hitung $>$ t_tabel atau 5,50 >1,99.

Karena t_hitung $>$ t_tabel yaitu 5,50 > 1,99 sehingga H_0 dditolak ddan H_1 diterima hal ini berarti terdapat perbedaan hasil belajar matematika diantara kelaseeksperimen dan kelaskkontrol. iPerbedaan tersebut bisa dilihatt dari nilai rata-rata kelaseeksperimen yang diajarkan dengan menggunakan pendekatan realistic mathemathic education secara e-learning yaitu 76,67, lebihttinggi dari nilairrata-rata kelaskkontrol yang diajarkan dengan menggunakan pendekatan saintifik secara e-learning yaitu 63,89.

Hal ini disebabkan karena pendekatan realistic mathemathic education pembelajarannya fokus pada hal-hal yang nyata menurut peserta didik, serta memfokuskan padakketrampilan,bberdiskusi serta berargumentasi, dengan itu peserta didik bisa menerapkan sistematika dalam menyelesaikan permasalahan secara mandiri atau berkelompok. Berdasarkan lhasil penelitian ini dapat ditarik kesimpulann bahwa terdapat ppengaruh

Copyright $@ 2021$

Buana Matematika :

Jurnal Ilmiah Matematika dan Pendidikan Matematika 
pendekatan realistic mathemathic education secara e-learning terhadap hhasil belajar matematika pada mmateri sistem pertidaksamaan linear dua variabel di kelas X SMA Negeri 1 Menganti tahun pelajaran 2020/2021.

\section{Simpulan}

Dari hasilaanalisis data dan ppembahasan yang ttelah dideskripsikan oleh peneliti pada babIIV maka didapatkan sebuah kesimpulkan bahwa terdapat pengaruh pendekatan realistic mathemathic education secara e-learning terhadap hasil belajar matematika pada materi sistem pertidaksamaan linearddua variabell di kelasXX SMA Negeri 1 Menganti tahun pelajaran 2020/2021. Penelitiank ini belumm maksimal karena itu Bagi peneliti lain yang akan melakukann penelitian yang samaa dengan penelitian ini, artikel ini dapat digunakan sebagai salah satu acuan, sangat diharapkan agar meningkatkan dan mengembangkan penelitian ini dengan cara mempersiapkan sajian materi lain dan lebih memaksimmalkan penelitiannya guna mengembangkan hasil belajar matematika kedepannya.

\section{Daftar Pustaka}

Astutik, E. P., \& Fitriatien, S. R. (2016). Metode Statistika. Adibuana University Press.

Budiman, H. (2017). Peran Teknologi Informasi dan Komunikasi Dalam Pendidikan. Al-Tadzkiyyah: Jurnal Pendidikan Islam, 8, 25-30. https://doi.org/10.6027/9789289336048-6-da

Fitriani, P., \& Permana, R. (2019). Pengaruh Realistic Mathemathic Education (RME) dengan Teknik Pair Cheks pada Materi Pecahan terhadap Prestasi Siswa SD. Indonesian Journal of Primary Education, 3(2), 73-82. http://ejournal.upi.edu/index.php/IJPE/index

Hasan, F., Pomalato, S. W. D., \& Uno, H. B. (2020). Pengaruh Pendekatan Realistic Mathematic Education (RME) terhadap Hasil Belajar Matematika Ditinjau dari Motivasi Belajar. Jambura Journal of Mathematics Education, 1(1), 13-20. https://doi.org/10.34312/jmathedu.v1i1.4547

Ibrahim, D. S., \& Suardiman, S. P. (2014). Pengaruh Penggunaan E-Learning Terhadap Motivasi Dan Prestasi Belajar Matematika Siswa Sd Negeri Tahunan Yogyakarta. Jurnal Prima Edukasia, 2(1), 66. https://doi.org/10.21831/jpe.v2i1.2645

Kusumawati, E., \& Morina Turisia, T. (2014). Kemampuan Siswa Dalam Memecahkan Masalah Matematika Menggunakan Pendekatan Pendidikan Matematika Realistik (PMR) dan Mekanistik. Journal of Chemical Information and Modeling, 53(9), 1689-1699.

Copyright $@ 2021$

Buana Matematika :

Jurnal Ilmiah Matematika dan Pendidikan Matematika 
Muchsin, H., Hairun, Y., \& Jalal, A. (2020). Analisis Kesalahan Konsep dalam Menyelesaikan Soal Sistem Pertidaksamaan Linear Dua Variabel (Sptldv) pada Studi Kasus Siswa Kelas X MIA6 SMANegeri 4 Kota Ternate Tahun Pelajaran 2019/2020. 4(1), 18-27.

Musfiqon, \& Nursyansyah. (2015). Pendekatan saintifik. Nazamia Learning Center.

Ningsih, S. (2014). Realistic Mathematics Education: Model Alternatif Pembelajaran Matematika Sekolah. Jurnal Pendidikan Matematika, 1(2), 73. https://doi.org/10.18592/jpm.v1i2.97

Nolaputra, A. P., Wardono, \& Supriyono. (2018). Analisi Kemampuan Literasi Matematika pada Pembelajaran PBL Pendekatan RME Berbantuan Schoology Siswa SMP. PRISMA: Prosiding Seminar Nasional Matematika, 1, 18-32.

Savitri, E., Studi, P., Matematika, P., \& Purworejo, U. M. (2018). Analisis Kesalahan Siswa dalam Menyelesaikan Masalah Sistem Pertidaksamaan Linear Dua Variabel Berdasarkan Analisis Newman. 6-11.

Sugiyono. (2015). Metode Penelitian Pendidikan Pendekatan Kuantitatif, Kualitatif, dan RED. Alfabeta.

Sukri, Y., \& Widjajanti, D. (2015). Pengaruh Pendekatan RME terhadap Motivasi dan Prestasi Belajar Siswa SD Melalui Pembelajaran Tematik-Integratif. 3, 227238.

Wijaya, I., \& Arsyah, R. H. (2015). Pengaruh Pembelajaran E-Learning Berbasis Edmodo Terhdap Hasil Belajar Simulasi Digital Kelas X SMK Negeri 9 Padang. Majalah Ilmiah UPI YPTK, 22(1), 21-33.

Zakia, A. R., Djamahar, R., \& Rusdi, R. (2019). Pengaruh Pembelajaran Berbasis Masalah Menggunakan Media Sosial E-Learning Terhadap Hasil Belajar Siswa Sekolah Menengah Pada Sistem Pencernaan. JPBIO (Jurnal Pendidikan Biologi), 4(1), 21-28. https://doi.org/10.31932/jpbio.v4i1.395

\section{Riwayat Hidup Penulis}

\section{Findy Soraya}

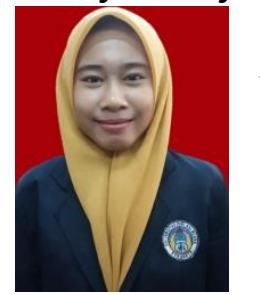

Lahir di kota Gresik, 02 Maret 1999. Penulis adalah pengajar bimbingan belajar priva. Studi S1 bidang Pendidikan Matematika pada Universitas PGRI Adi Buana Surabaya, Surabaya, lulus S1 pada tahun 2021.

Copyright $(0) 2021$

Buana Matematika :

Jurnal Ilmiah Matematika dan Pendidikan Matematika 


\section{Restu Ria Wantika}

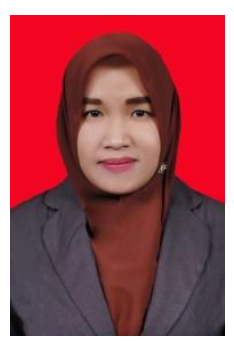

Lahir di kota Surabaya, 22 November 1989. Penulis adalah pengajar pada S1 Program Studi Pendidikan Matematika, Fakultas Sains dan Teknologi, Universitas PGRI Adi Buana Surabaya. Menyelesaikan Studi S1 pada tahun 2011 Pendidikan Matematika Universitas Negeri Surabaya. Selanjutnya melanjutkan S2 Matematika Institut Teknologi Sepuluh Nopember Surabaya, lulus pada tahun 2015. Dan saat ini edang menempuh Studi S3 Pendidikan Matematika Universitas Negeri Surabaya. Penulis juga berhasil meraih hibah dari Kemenristek Dikti tahun 2018 pada Skema Dosen Pemula. 
Jurnal Ilmiah Matematika dan Pendidikan Matematika Vol. 11 No. 2 (2021)

Copyright $(0) 2021$

- Buana Matematika :

Jurnal Ilmiah Matematika dan Pendidikan Matematika 